IOSR Journal of Pharmacy

e-ISSN: 2250-3013, p-ISSN: 2319-4219, www.iosrphr.org

Volume 2 Issue 5 || || Sep-Oct. 2012 || $\mid$ PP. 01-07

\title{
Effect of microgravity on living system
}

\author{
Miss Shivani Sharma \\ Affiliation: Institute of Applied Medicine and Research, Ghaziabad, U.P., India. \\ (J-4200-2012)
}

\begin{abstract}
Our planet Earth has been proliferating with life for billion years and life has survived in the constant influence ofgravity. So it's a major question if the gravity has an influence over the major processes and mechanisms of earth-inhabiting organisms and the environment. Ever since the first space missions and many ground-based experiments, it is a well-established fact now thatthe immune cell function is severely suppressed in $0 \mathrm{~g}$, which makes the cells of the immune system a noble model organism to investigate the influence of gravity on life at the cellular and molecular level. Also, it has been previously found that osteoblast growth is reduced in microgravity and the ability to be activated to grow is significantly changed during a spaceflight. The studies have suggested that quiescent osteoblasts are slower to enter the cell cycle in microgravity and that the lack of gravity itself may prove to be a significant factor in bone loss during a spaceflight. Thus, by understanding the impact of gravity on cellular functions on Earth one can conclude not only important information about role of gravity on the development of life on Earth, but also for therapeutic and preventive strategies to cope successfully with problems relating to immune system and its defence mechanisms during space exploration. In this paper, I review the knowledge about the question i.e. if and how cellular signal transduction pathways in the cells of immune system depends on the existence of gravity and how gravity plays a role in bone growth, that has been perceived till date.
\end{abstract}

\section{CHANGED IMMUNE RESPONSES IN SPACE}

The first report about disturbed immune response that was obtained in 70s indicated reduced activity of blood lymphoid cells discovered in crew members of Soyuz, Apollo and Skylab spaceships [1,2]. A virus, Varicella zoster which stays latent after the primary infection but gets activated in organisms with a suppressed immune system such as in patients having AIDS or cancer, has been reported to become sub clinically active in astronauts [3,4]. Also, it is well known that gravity can be perceived by gravireceptors that is a statocyst-like organelles or gravisensitive ion channels in the cell membrane. Although in unicellular organisms in which gravisensitivity plays an important role in signal transduction and cell behaviour [5, 6] for example in Paramecium or loxodes, the mechanisms of these processes are still not properly known but further studies and research work is in progress.It is well known that proliferative response of $\mathrm{T}$ lymphocytes after mitogenic stimulation is strongly supressed when in microgravity after the pioneering discovery of Cogoli et al almost 20 years ago in a space lab mission $[7,8]$.

Gravitational unloading: Changes observed in lymphocytes

Before getting onto the changes observed in $\mathrm{T}$ lymphocytes attributed to gravitational unloading, a clear distinction must be made between two kinds of experiments: (i) In vitro experiments conducted with cells purified from the peripheral blood of test subjects obtained before flight and then exposed inflight to mitogens and other activators, and (ii) Ex vivo experiments conducted with lymphocytes obtained from crew members of space missions exposed to mitogens prior to and after space flight [8]. Where the first approach can be considered as a basic research in cell biology in space; the second one is an approach to identify the effects of the stress of spaceflight on the immune response of astronauts. The data and results obtained from in vitro experiments have shown that lymphocyte activation is nearly totally suppressed in microgravity. This activation depression is confirmed by experiments conducted on Earth in the fast rotating clinostat. Apparently, when lymphocytes were cultured at $10 \mathrm{~g}$ in a centrifuge, activation increased. In microgravity cell adhesion might get reduced, thus partly accounting for fact that the cell activation is decreased which was confirmed later that the results were due to the simultaneous activation of T- and B-cells by concanavalinA. The reduced activation observed in lymphocytes from crewmembers of space missions can be attributed to both the physical and psychological stress of spaceflight. This observation was later confirmed by investigations on subjects undergoing stress on Earth [8].

Since the study of the function of immune cells in microgravity has been a major topic for research and studies for more than 20 years in various labs including the major ones like NASA. After several succeeding experiments it has become clear that the immune system is highly depressed in more than $50 \%$ of the astronauts during and after space flight. Also, a dramatic change was observed in the activation of $\mathrm{T}$ lymphocytes 
by mitogens in vitro. Cogoli et al conducted gravitational studies in Spacelab laboratory, in MIR station and in sounding rockets and on the ground in the clinostat and the centrifuge. The major experimental approaches to be included were: (i) Ex vivo studies conducted with blood samples taken from astronauts; (ii) in vivo studies based on the application of seven antigens to the skin of the astronauts; (iii) in vitro studies performed with immune cells taken from the blood of healthy donors (not astronauts). The data \& results from these in vivo and ex vivo studies are in agreement with those of other laboratories and thus clearly show that the immune function is depressed in the majority i.e. $50 \%$ of astronauts due to the stress of space flight rather than by a direct influence of gravity on the cell. Thus one can say that Immune suppression may become a critical and severe hazard on flights of long duration on space stations or to other planets. Further, in vitro experiments show that a dramatic depression of activation is observed in the cultures of free-floating lymphocytes and monocytes by the mitogen concanavalin A, while on the other hand, when the cells are attached to micro carrier beads, activation is more than doubled. Therefore, such effects may be attributed to both direct and indirect effects of gravity or to be clearer, gravitational unloading on basic biological mechanisms of the cell. Although the in vitro data are very significant to clarify major aspects of the signal transduction of T cell activation, they are still not quite descriptive of the changes of the immune function of the astronauts [9].

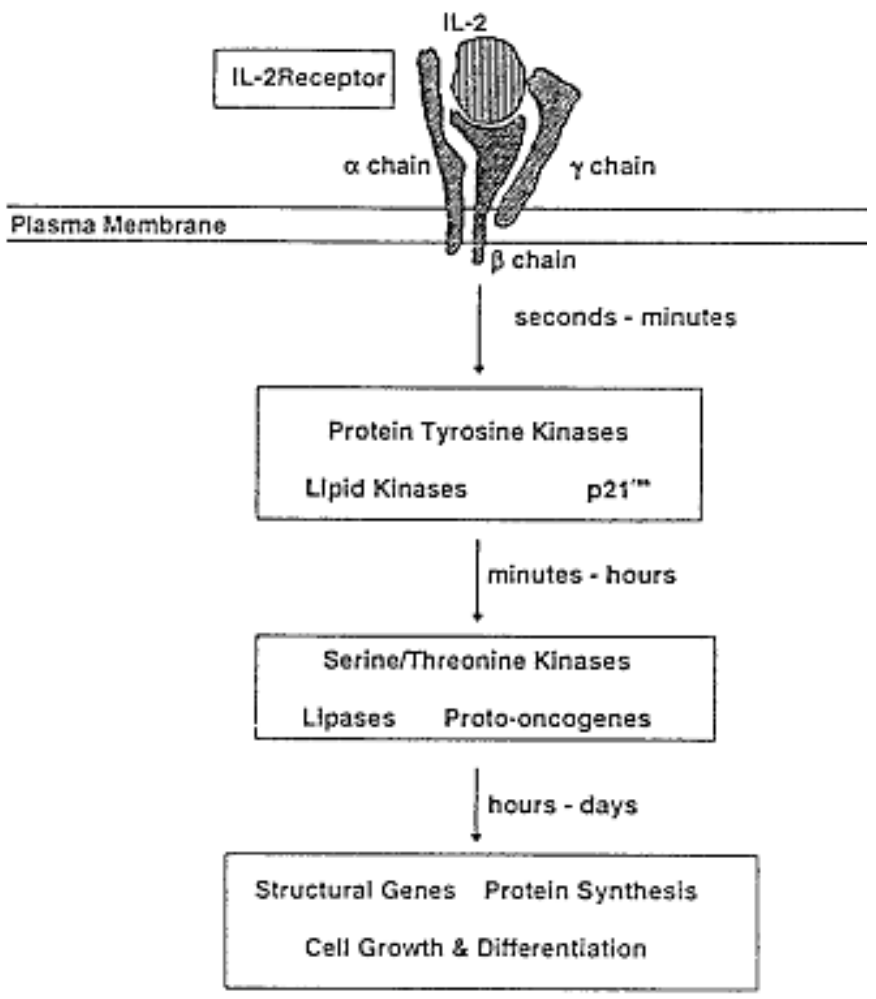

\section{Cell-to-Cell Communication and Signal Transduction is disturbed in microgravity.}

Several studies report alterations in signal transduction in lymphocytes. In lymphocytes, microgravity was found to be affecting the protein kinase $\mathrm{C}[11,12]$. Although the delivery of first activation signal, patching and capping of conA-binding membrane proteins seemed to occurr normally in spaceflight [13]. These findings have suggested the existence of gravisensitive cellular targets upstream from PKC and downstream from the TCR/CD3. T cells were subjected to simulated microgravity provided by the random-positioning machine (RPM) and their DNA array analysis was done that revealed an alteration of several signal moduls, in particular NF-kB and MAPK-signalling [14]. Also the expression of the early oncogenes c-fos, c-myc and c-jun is found to be inhibited during spaceflight [15].

Impaired monocyte function: During the spacelab-mission SLS-1, monocytes were found to loose their capability of secreting IL-1 [16] and of expressing IL-2-receptor [26]. In gene induction associated with differentiation of monocytes into macrophages, examination of gene expression of monocytes under real microgravity demonstrated significant changes [18]. Kaur et al. [19] conducted a study in which he performed experiments on monocytes isolated from astronauts before and after a mission and then compared the results with control groups. They found a reduction of phagocytosis and also, a reduced oxidative burst and degranulation-capacity. Meloni et al. [20] recently demonstrated that simulated weightlessness leads to huge alterations in the cytoskeleton of monocytes, which in turn influences motility and also, recently revealed during 
an ISS experiment, a severe reduction in the locomotion ability of monocytic cells in microgravity [21]. Further studies with natural killer cells in simulated microgravity and in real microgravity on board of the ISS, revealed significant results; one of them being that neither cytotoxic effects nor interferon production is altered in microgravity [22].

\title{
Cell migration in microgravity
}

Neutrophil locomotion is integral for immune effector function, because the cells have to leave the blood vessels and then navigate to places of infection and injury to fulfil their main task of phagocytosis thus making cell migration an important factor. They are one of the most important cells regulating the immune response, because they can, in several ways, influence both induction and the effector stage of immunological reactions. Several studies have provided evidence of a disturbed function of neutrophil granulocytes: Returning astronauts of spaceflight missions exhibited a strong increase of neutrophil granulocytes immediately after landing [23,24], and a 10-fold decrease was seen in neutrophil chemotactic assays showed in the optimal doseresponse after landing [25].

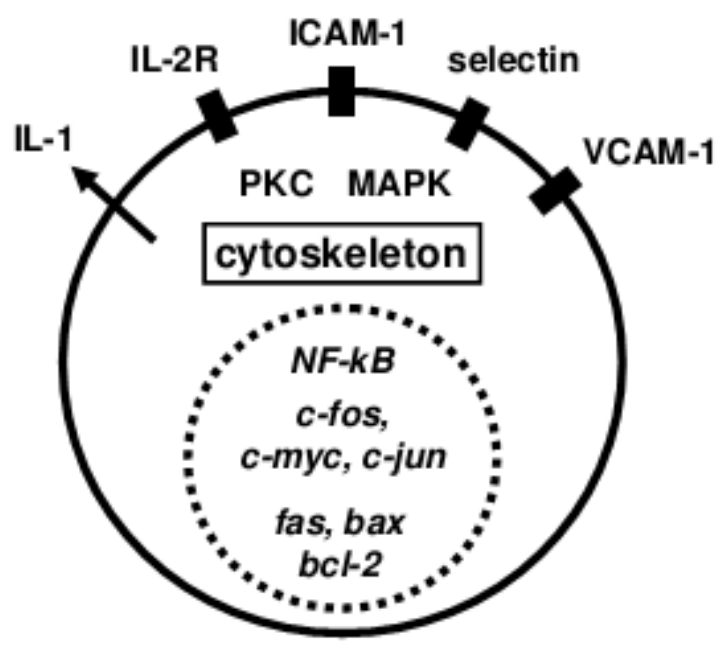

\begin{abstract}
Figure I
Gravi-sensitive signal transduction elements in mammalian cells. Gravi-sensitive signal transduction elements has been detected at the cell surface, such as VCAM-I (Vascular cell adhesion molecule I), ICAM-I (Intercellular adhesion and molecule I) and IL-2R (interleukin-2 receptor), in the cytoplasma such as PKC (protein kinase C) and MAPK (mitogen-activated protein kinases) and in the nucleus such as expression of c-fos, c-jun and other genes. Microgravity severely affects also the cytoskeleton. However, the primary molecular mechanisms how microgravity influences cell signaling are unknown.
\end{abstract}

[Fig 1 Source: 59]

Cell migration is an essential and must characteristic of life. Multicellular organisms must be motile to obtain nourishment, avoid being eaten in their own right and for their own good, respond to changes in environment and reproduce. In previous studies using simulated microgravity, an inhibition of lymphocyte locomotion was being demonstrated by changes in gravity demonstrated through type I collagen [26,27], and a decreased migration potential was observed in culture of human bone marrow CD34+ cells using NASA 's rotating wall vessels [28]. An altered movement in real microgravity was shown for leukocytes and Jurkat T cells, too $[29,30]$, whereas their underlying signal transduction mechanisms are still unknown. On the other side, $\mathrm{T}$ cells became more motile after being cultured in $10 \mathrm{~g}$ hyper gravity [31].

The cytoskeleton isan important factor in cell migration and is responsible for giving a cell its shape and for generating the forces that are required for cell motility. It is an internal network of at least three types of cytosolic fibres. These are actin filaments, microtubules and intermediate filaments. Actin being one of the most highly conserved and abundant eukaryotic proteins, is constantly polymerized and then depolymerized within the cells to invoke cellular motility, then tissue formation and finally repair [32,33]. Actin dynamics are considered to be the main component of the cytoskeleton and are responsible for cell motility. It has been shown to be essential for the migration of $\mathrm{T}$ lymphocyte cells as well as neutrophil granulocyte migration, a conclusion readily assumed given the fact that actin-depolymerizing drugs inhibit cellular motility [34,35]. Apparently, as 
microtubule-disrupting drugs such as colchicine even induce the migration of neutrophils, an intact microtubule network does not appear to be required for neutrophil migration. [36], probably by inducing changes in the actin network.

\section{INFLUENCE OF MICRO-GRAVITY ON CYTOSKELETON}

Multiple investigators have reported that this complex network of fibres i.e. the cytoskeleton is sensitive to environmental factors such as microgravity and altered gravitational forces [37]. Several studies have demonstrated slight modifications of the actin and microtubule cytoskeleton in microgravity. Already it has been shown that a few minutes of simulated weightlessness provided by 2D-clinorotation affect the cytoskeleton of lymphocytes, astrocytes, etc. [38,39]. Morphological differences have been observed both in the microtubule and actin components of the cytoskeleton in cells grown in real and simulated microgravity [38,40]. Gruener and Hughes-Fulford reported earlier that actin reorganization responded to the gravity level and in turn, showed abnormal assembly of actin stress fibres during spaceflight [41-43]. In human mesenchymal stem cells, within three hours of initiation of modelled microravity, F-actin stress fibers were found to be disrupted [44]. On the contrary, in Jurkat cells microgravity did not alter the structure of actin but formed vimentin[30]. Other studies have shown that micro-tubules are gravity sensitive, too [45]. Microtubule self-assembly was found to be inhibited in the absence of gravity in space [46], and Lewis et al. observed that the extension of microtubule filaments from a poorly defined centrosome in human Jurkat cells [40]. Moreover, when cancer cells were grown under microgravity, they exhibited an increased and highly disorganized vimentin as well as altered microtubules $[47,48]$.

Many components of signal transduction pathways are known to regulate the cytoskeleton [11,40,42]. With regard to migration, neutrophils are the fastest moving cells among all with a speed maximum of 15 to 20 $\mu \mathrm{m} / \mathrm{min}$ [49], and the starting signal for their migration to sites of infection is provided by early proinflammatory cytokines such as the bacterial peptide fMLP [50]. The bacterial peptide fMLP is the major peptide which is chemotactic and is produced by E.coli and known to be a strong stimulator for the migration of neutrophil granulocytes. fMLP binds receptors and in turn, activates a class of G-protein-coupled receptors. Ligand binding then leads to the activation of two signalling pathways: (i) the activation of the PLC-gamma generates inositol-1, 4, 5-phosphate $\left(\mathrm{IP}_{3}\right)$ and diacylglycerol (DAG), which leads to IP3 mediated release of intra-cellular calcium in the endoplasmic reticulum and DAG-mediated activation of the protein kinase $\mathrm{C}$ (PKC). These are key events for the regulation of locomotion [50-52]. The second pathways is: (ii) the activation of the adenylyl cyclase leads to an increase of cytosolic cAMP, which in turn leads to an activation of the sarcoplasmatic/endoplasmatic reticulum calcium ATPase (SERCA). Thus, stimulation of neutrophils with fMLP activates a signal transduction pathway ultimately resultinginto an elevation of cytosolic calcium which has been proved to be essential for the essential development of actin-based migration [53]. In addition, observations of migrating neutrophils within a 3D collagen matrix showed a significant and frequent increase of calcium in those parts of the cells that underwent shape changes a few seconds later. Also, visualization of the calcium signal was shown as to be a directional marker for the orientation of neutrophils migration in a 3D space [50]. In context of cell migration, the inhibition of lymphocyte locomotion was observed under microgravity and it was found that the culture conditions could be reversed by prior and proper activation with phorbolmyristate acetate (PMA), which is known to directly activate the PKC [27].

\section{Changes in gene expression caused by low gravity forces:}

Since life on Earth evolved in a $1-G$ environment, a hypothesis was made that says that the gravity itself may have an effect on bone growth. The pre-flight data obtained from a space flight focused on the changes in growth that maybe directly due to the lack of gravity [58]. In these ground experiments, the MC3T3E1 osteoblasts placed on coverslips and kept in Bio-rack plunger boxes were allowed to grow in a serum deprived state as done on the shuttle experiments of STS-76. The cells were subjected to 3-G gravitational forces for 8 minutes. It is known that $\mathrm{PGE}_{2}$ and $\mathrm{PGI}_{2}$ are released during exercise, therefore giving the thought that in microgravity, the same pathway may be implicated in bone loss. [58]

\section{Low levels of gravity for a short period cause changes in gene expression:}

Serum- deprived mouse osteoblastic cells (MC3T3-E1) were centrifugedunder a regime designed to simulate a Space Shuttle launch (maximum of $3 \mathrm{~g}$ ). Using RT-PCR, mRNA levels were determined for 9 genes involved in bone growth and maintenance. 30 minutes after centrifugation, the mRNA for early response gene, c-fos, was found to be $80 \%$ increased significantly $(\mathrm{P}<0.05)$. The results suggested that the increase in $\mathrm{c}$-fos mRNAin response to gravitational loading is a sole result of mechanical stimulation[58]. These results indicated that a small magnitude mechanical loading, such as that experienced during a Shuttle launch, can alter mRNA levels in quiescentosteoblastic cells [54]. Changes in gene expression due to mechanical force of gravity can be caused by several components\& factors of the cell. The mechanisms by which mammalian cells respond to 
gravitational signalsare still unknown. However, it isknown that there are several mechano transducers seen in

Figure 2 in the cell that may be responsible.

Figure 2. Possible pathways for mechanotransducers

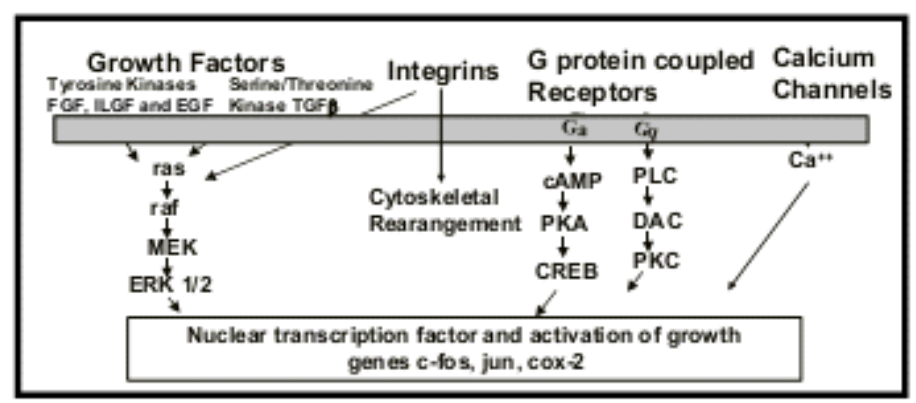

[Fig. 3 source: 58 ]

The study suggested that the cells subjected to the $0-G$ environment did not enter the growth phase of the cell cycle at all since cox-2 was found to bequite depressed in the microgravity samples [58]. In later studies, the deLaat 's group demonstrated that the nuclear responses to protein kinase $\mathrm{C}$ signal transduction were sensitive to gravity changes (55). In these studies, they demonstrated that EGF and phorbol ester (TPA) induced gene expression of c-fos and c-jun were changed by microgravity, while the calcium response was not changed, thus implicating the diacylglyceride (DAG) portion of the PKC signal transduction.

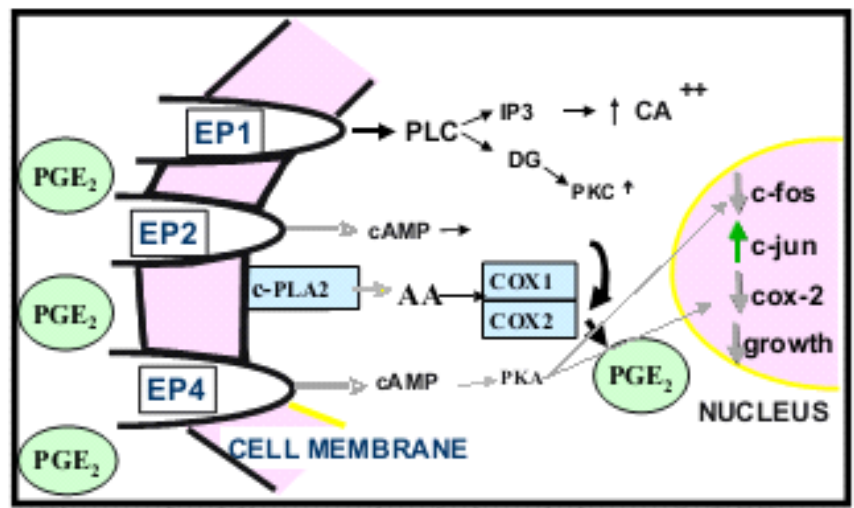

\footnotetext{
Figure 3: Microgravity induced loss of $\mathrm{PGE}_{2}$

signaling pathway in microgravity It is possible that changes in the $\mathrm{PGE}_{2}$ receptors could inhibit recognition of $\mathrm{PGE}_{2}$ in microgravity. As seen in the figure above, if $\mathrm{PGE}_{2}$ were unable to bind to the EP receptors, this would result in a high level of $\mathrm{PGE}_{2}$ in the media and an inhibition of signaling through the 7domain transmembrane G-coupled prostaglandin receptor pathway (shown in gray lines).
}

[Fig. 3 Source: 58]

Thus, it was shown that microgravity (lack of mechanical stress) changes prostaglandin content and various other factors including response to prostaglandin, change in morphology and gene expression in osteoblasts [58]. It is most likely to happenthat decreased gravity induced mechanical stress coupled with other significant changes in signal transduction directly attribute to astronaut bone loss during spaceflight. It has been shown through both in vivo and in vitro experiments that blocking the prostaglandin signalling pathway can inhibit new bone formation in humans $(56,57)$. The resulting down-regulation of prostaglandin growth pathway in microgravity is most likely to be considered as a key molecular component in the cause of space osteoporosis. In these studies, it has been demonstrated that in 8 of 9 genes studied microgravity causes inhibition of fatal calf sera stimulation of mRNA. In 5 of the 8 inhibited messages, artificial or to be clear, simulated gravity was able to restore message levels to normal. These data have suggestedthat artificial gravity amendsignificant bone loss in astronauts in spaceflight to enable mankind to go to Mars.

\section{ACKNOWLEDGEMENT}

I would like to thank Mrs.Aruna Sharma, Mr.SiddharthVasistha and Ms.ManjuLata without whose kind support, I would not have been able to write this review paper. 


\section{REFERENCES}

[1]. Konstantinova IV, AntropovaYN ,Legenkov VI, Zazhirey VD:Study of reactivity of blood lymphoid cells in crew members of the Soyuz-6, Soyuz-7 and Soyuz-8 spaceships before and after flight. space BiolMed 1973, 7: 48-55.

[2]. Kimzey SL: Hematology and immunology studies. In Biomedical results from Skylab. NASA-SP-377 National Aeronautics and Space Administration; 1977:249-282.

[3]. Cohrs RJ, Mehta SK, Schmid DS, Gilden DH, Pierson DL: Asympto-matic reactivation and shed of infectious varicella zoster virus in astronauts. J Med Virol 2008, 80:1116-1122.

[4]. Mehta SK, Cohrs RJ, Forghani B, Zerbe G, Gilden DH, Pierson DL: Stress-induced subclinical reactivation of varicella zoster virus in astronauts. J Med Virol 2004, 72:174-179.

[5]. Häder DP, Hemmersbach R, Lebert M: Gravity and the behaviour of uni-cellular organisms Cambridge, New York (United Kingdom, USA): Cambridge University Press; 2005.

[6]. Hemmersbach R, Hader DP: Graviresponses of certain ciliates and flagellates. FASEB J 1999, 13(Suppl): S69-75.

[7]. Cogoli A, Tschopp A, Fuchs-Bislin P: Cell sensitivity to gravity. Science 1984, 225: 228-230.

[8]. Cogoli A, Bechler A, Mueller O, Hunzinger E: Effects of Micrograv-ity on Lymphocyte Activation. Exp 30011985, STS-61-A, Spacelab D1: Erasmus Experiment Archive 1996.

[9]. Cogoli A: Gravitational physiology of human immune cells: a review of in vivo, ex vivo and in vitro studies. J GravitPhysiol 1996, 3: 1-9.

[10]. Grove DS, Pishak SA, Mastro AM: The effect of a 10-day space flight on the function, phenotype, and adhesion molecule expression of splenocytes and lymph node lymphocytes. Exp Cell Res 1995, 219: 102-109.

[11]. Hatton JP, Gaubert F, Cazenave JP, Schmitt D: Microgravity modi-fies protein kinase C isoform translocation in the human monocytic cell line U937 and human peripheral blood T-cells. J Cell Biochem 2002, 87:39-50.

[12]. Schmitt DA, Hatton JP, Emond C, Chaput D, Paris H, Levade T, Cazenave JP, Schaffar L: The distribution of protein kinase $C$ in human leukocytes is altered in microgravity. FASEB J 1996, 10:1627-1634.

[13]. Cogoli A, Cogoli-Greuter M: Membrane binding of concanavalin A. Erasmus Experiment Archive; Exp. 10.04.1989, MASER 3

[14]. Boonyaratanakornkit JB, Cogoli A, Li CF, Schopper T, Pippia P, Galleri G, Meloni MA, Hughes-Fulford M: Key gravity-sensitive signaling pathways drive T cell activation. FasebJ 2005, 19:2020-2022.

[15]. Bräucker R, Cogoli A, Hemmersbach R: Graviperception and Graviresponse at the Cellular Level. In Astrobiology The Quest for the Conditions of Life Edited by: Horneck G, Baumstark-Khan C. BerlinHeidelberg New York: Springer-Verlag; 2002:287-333.

[16]. Cogoli A: The effect of hypogravity and hypergravity on cells of the immune system. J LeukocBiol 1993, 54:259268.Hashemi BB, Penkala JE, Vens C, Huls H, Cubbage M, Sams CF: T cell activation responses are differentially regulated during clino-rotation and in spaceflight. FASEB J 1999, 13:2071-2082.

[17]. Hughes-Fulford M, Chang T, Li CF: Effect of Gravity on Monocyte Differentiation. 10th ESA Life Sciences Symposium/29th Annual ISGP Meeting/24th Annual ASGSB Meeting/ELGRA Symposium "Life in Space for Life on Earth". Angers, France 2008.

[18]. Kaur I, Simons ER, Castro VA, Ott CM, Pierson DL: Changes in monocyte functions of astronauts. Brain BehavImmun 2005, 19:547-554.

[19]. Meloni MA, Galleri G, Pippia P, Cogoli-Greuter M: Cytoskeleton changes and impaired motility of monocytes at modelled low gravity. Protoplasma 2006, 229: 243-249.

[20]. Meloni MA, Galleri G, Pani G, Saba A, Pippia P, Cogoli-Greuter M: Effects of Real Microgravity Aboard International Space Sta-tion on Monocytes Motility and Interaction with T-Lym-phocytes. 10th ESA Life Sciences Symposium/29th Annual ISGP Meeting/24th Annual ASGSB Meeting/ELGRA Symposium "Life in Space for Life on Earth". Angers, France 2008.

[21]. Buravkova LB, Rykova MP, Grigorieva V, Antropova EN: Cell inter-actions in microgravity: cytotoxic effects of natural killer cells in vitro. J GravitPhysiol 2004, 11:P177-180.

[22]. Kaur I, Simons ER, Castro VA, Mark Ott C, Pierson DL: Changes in neutrophil functions in astronauts. Brain BehavImmun 2004, 18:443-450.

[23]. Cogoli-Greuter M, et al. : Mitogen binding, cytoskeleton pat-terns and motility of T-lymphocytes in microgravity. Life sci-ences experiments performed on sounding rockets (1985-1994). ESA SP-1206:59-70.

[24]. Stowe RP, Sams CF, Mehta SK, Kaur I, Jones ML, Feeback DL, Pierson DL: Leukocyte subsets and neutrophil function after short-term spaceflight. J LeukocBiol 1999, 65:179-186.

[25]. Pellis NR, Goodwin TJ, Risin D, McIntyre BW, Pizzini RP, Cooper D, Baker TL, Spaulding GF: Changes in gravity inhibit lymphocyte locomotion through type I collagen. In Vitro Cell DevBiolAnim 1997, 33:398-405.

[26]. Sundaresan A, Risin D, Pellis NR: Loss of signal transduction and inhibition of lymphocyte lo comotion in a ground-based model of microgravity. In Vitro Cell DevBiolAnim 2002, 38:118-122.

[27]. Plett PA, Abonour R, Frankovitz SM, Orschell CM: Impact of mod-eled microgravity on migration, differentiation, and cell cycle control of primitive human hematopoietic progenitor cells.ExpHematol 2004, 32:773-781.

[28]. Cogoli-Greuter M, Meloni MA, Sciola L, Spano A, Pippia P, Monaco G, Cogoli A: Movements and interactions of leukocytes in micro-gravity. J Biotechnol 1996, 47:279-287.

[29]. Sciola L, Cogoli-Greuter M, Cogoli A, Spano A, Pippia P: Influence of microgravity on mitogen binding and cytoskeleton in Jur-kat cells. Adv Space Res 1999, 24:801-805.

[30]. Galimberti M, Tolic-Norrelykke IM, Favillini R, Mercatelli R, Annunzi-ato F, Cosmi L, Liotta F, Santarlasci V, Maggi E, Pavone FS: Hyper-gravity speeds up the development of T-lymphocyte motility. EurBiophysJ 2006, 35:393-400. 
[31]. Feldner JC, Brandt BH: Cancer cell motility - on the road from c-erbB-2 receptor steered signaling to actin reorganization. Exp Cell Res 2002, 272: 93-108.

[32]. Lee JS, Gotlieb AI: Microtubule-actin interactions may regulate endothelial integrity and repair. CardiovascPathol 2002, 11:135-140.

[33]. Hofman P, d'Andrea L, Guzman E, Selva E, Le Negrate G, Far DF, Lemichez E, Boquet P, Rossi B: Neutrophil Factin and myosin but not microtubules functionally regulatetransepithelial migration induced by interleukin 8 across a cultured intesti-nal epithelial monolayer. Eur Cytokine Netw 1999, 10:227-236.

[34]. Verschueren H, Taelen I van der, Dewit J, De Braekeleer J, De Baet-selier P, Aktories K, Just I: Effects of Clostridium botulinum $\mathrm{C} 2$

[35]. toxin and cytochalasin D on in vitro invasiveness, motility and F-actin content of a murine T-lymphoma cell line. Eur J Cell Biol 1995, 66:335-341.

[36]. Niggli V: Microtubule-disruption-induced and chemotactic-peptide-induced migration of human neutrophils: implica-tions for differential sets of signalling pathways. J Cell Sci 2003,

[37]. 116: 813-822.

[38]. Schatten H, Lewis ML, Chakrabarti A: Spaceflight and clinorota-tion cause cytoskeleton an d mitochondria changes and increases in apoptosis in cultured cells. ActaAstronaut 2001, 49:399-418.

[39]. Uva BM, Masini MA, Sturla M, Prato P, Passalacqua M, Giuliani M, Tagliafierro G, Strollo F: Clinorotationinduced weightlessness influences the cytoskeleton of glial cells in culture. Brain Res 2002, 934: 132-139.

[40]. Uva BM, Strollo F, Ricci F, Pastorino M, Mason JI, Masini MA: Mor-pho-functional alterations in testicular and nervous cells sub-mitted to modelled microgravity. J EndocrinolInvest 2005,

[41]. 28:84-91.

[42]. Lewis ML, Reynolds JL, Cubano LA, Hatton JP, Lawless BD, Piepmeier EH: Spaceflight alters microtubules and increases apoptosis in human lymphocytes (Jurkat). FASEB J 1998, 12:1007-1018.

[43]. Gruener R, Roberts R, Reitstetter R: Reduced receptor aggrega-tion and altered cytoskeleton in cultured myocytes after space-flight. BiolSci Space 1994, 8: 79-93.

[44]. Hughes-Fulford M: Function of the cytoskeleton in gravisensing during spaceflight. Adv Space Res 2003, 32:1585-1593.

[45]. Hughes-Fulford M: Review of the biological effects of weight-lessness on the human endocrine system. Receptor 1993, 3: 145-154.

[46]. Meyers VE, Zayzafoon M, Douglas JT, McDonald JM: RhoA and cytoskeletal disruption mediate reduced osteoblastogenesis and enhanced adipogenesis of human mesenchymal stem cells in modeled microgravity. J Bone Miner Res 2005, 20:1858-1866.

[47]. Crawford-Young SJ: Effects of microgravity on cell cytoskele-ton and embryogenesis. Int J DevBiol 2006, 50:183-191.

[48]. Papaseit C, Pochon N, Tabony J: Microtubule self-organization is gravity-dependent. ProcNatlAcadSciUSA 2000, 97:8364-8368.

[49]. 47. Infanger M, Kossmehl P, Shakibaei M, Bauer J, Kossmehl-Zorn S, Cogoli A, Curcio F, Oksche A, Wehland M, Kreutz R, et al.: Simu-lated weightlessness changes th e cytoskeleton and extracel-lular matrix proteins in pap illary thyroid carcinoma cells. Cell Tissue Res 2006, 324: 267-277.

[50]. Vassy J, Portet S, Beil M, Millot G, Fauvel-Lafeve F, Gasset G, Schoe-vaert D: Weightlessness acts on human breast cancer cell line MCF-7. Adv Space Res 2003, 32:1595-1603.

[51]. Entschladen F, Zanker KS: Locomotion of tumor cells: a molec-ular comparison to migratin $\mathrm{g}$ pre- and postmitoticleuko-cytes. J Cancer Res ClinOncol 2000, 126: 671-681.

[52]. Lang K, Hatt H, Niggemann B, Zaenker KS, Entschladen F: A novel function for chemokines: do wnregulation of neutrophil migration. Scand J Immunol 2003, 57:350-361.

[53]. 51. Entschladen F, Niggemann B, Zanker KS, Friedl P: Differential requirement of protein tyrosine kinases and protein kinase $\mathrm{C}$ in the regulation of T cell locomotion in three-dimensional collagen matrices. J Immunol 1997 , 159: 3203-3210.

[54]. Schorr W, Swandulla D, Zeilhofer HU: Mechanisms of IL-8-induced Ca2+ signaling in human neutrophil granulocytes. Eur J Immunol 1999, 29:897-904.

[55]. Stossel TP: The E. Donnall Thomas Lecture, 1993. The machinery of blood cell movements. Blood 1994, 84:367-379.

[56]. Fitzgerald , J., and Hughes-Fulford, M., Gravitational loading of a simulated launch alters mRNA expression in osteoblasts, Exp Cell Res, 228, 168 (1996).

[57]. de Groot, R . P., Rijken, P. J., den Hertog, J., Boonstra, J., Verkleij, A. J., de Laat, S. W ., and Kruijer, W ., Nuclear responses to protein kinase C signal transduction are sensitive to gravity changes, Exp Cell Res, 197 , 87 (1991).

[58]. Forwood, M. R., Kelly, W . L., and Worth, N. F., Localisation of prostaglandin endoperoxi de H synthase (PGHS)-1 and PGHS- 2 in bone following mechanical loading in vivo, Anat Rec, 252, 580 (1998).

[59]. Forwood, M . R ., Inducible cyclo-oxygenase (COX-2) mediates the induction of bone formation by mechanical loading in vivo, J Bone Miner Res, 11,1688 (1996).

[60]. Millie Hughes-Fulford, Changes in gene expression in microgravity, Journal of Gravitational Physiology. Vol 8 (1) 2001.

[61]. Oliver Ulrich et al, Signal Transduction in cells of immune system, Cell Communication and Signaling2008, 6:9, published: 28 October 2008. 